\title{
An Approach to CLIL Through ICT Start Up CLIL Network Towards CLIL Project
}

\author{
Emanuela Leto \\ I C Laura Lanza Baronessa di Carini (PA), Carini, Italy
}

\begin{abstract}
The project towards CLIL (Content and Language Integrated Learning) was carried on during the school year 2015-2016 by a network of primary and low secondary schools located in the district of Carini Territory in Sicily. I had the chance to coordinate this network, named "Start Up CLIL", set up in order to promote and foster the use of CLIL approach as a tool to improve the quality of learning and teaching foreign language, in particular English in Italian schools. Students involved were students attending the last classes of primary and low secondary school. The theme chosen referred to History and Education to Citizenship. The approach was based on the use of ICT (Information Communications Technology) and of specific softwares and tools to build up interactive lessons on a predetermined path involving several disciplines. This choice has proven to be successful in terms of involvement and improvement in acquisition of language skills in students and in terms of collaboration among teachers. Moreover, the students realized the importance of learning a foreign language as a tool to communicate and to do things, acquiring at the same time digital skills in connection with language and disciplinary skills. I will give some examples of CLIL units and works and how the network teachers built them.
\end{abstract}

Keywords: CLIL, language teaching, ICT

\section{Introduction}

The project has been carried out during the school year 2015-2016 in a district made up of schools located in the territory of the town Carini near Palermo, Sicily, led by the school I C Laura Lanza Baronessa di Carini. In particular, the schools involved were I C Sferracavallo, D. D. Pallavicino, SMS Erice, I C Guttuso in Villagrazia, and I C Riso in Isola delle Femmine. The participants were more than 240 pupils, aged 9-10, attending the final class of Primary school, more than 300 pupils, aged 12-13, attending the final class of Low Secondary school, and around 60 teachers of different levels and subjects, in particular English, Science, History, Italian and Geography, Citizenship, and Ict as a support. The chosen theme was "Historical, Geographical and Scientific events during the last two centuries in Europe, in particular, after the two World Wars and the birth of the European Union". A training course for the teachers involved was carried on, whose aims were to provide an effective framework on how to plan simple CLIL lessons based on a virtual platform (EDMODO in the specific) to use also in their classes in order to share the planned work. The course lasted six months and as the level of

Emanuela Leto, master's degree in Foreign Language and Literature, referent teacher in Istituto Comprensivo Laura Lanza, Baronessa di Carini, Carini (PA), Italy. 
teachers involved was not suitable to the one which was required-A2/B1 - it was stated that the subject teachers had to work in pairs with foreign language teachers so that the linguistic gap and the specific discipline gap could be reciprocally filled. The project was also disseminated among all the school committees as a new challenge to improve the quality of foreign language teaching and to promote a multidisciplinary learning approach. The main assumption was that CLIL is a methodology, a means to teach and to learn foreign languages and using such approach so late in the school curriculum, the way it is in the Italian school system, in the last years of high school, does not ensure an effective success. Otherwise, a closer approach to CLIL as a new method to learn foreign languages since Primary school should be strongly advised also in terms of increasing motivation in students.

\section{How to Plan CLIL Lessons}

The starting point to be discussed and exploited was:

(1) Level of English of the students;

(2) Level of content knowledge; materials.

As the level of English was quite weak, it was better to start with a more language-oriented approach, focusing on the vocabulary related to the content areas.

Materials had to be set according to the level of the students focusing on the main contents related to the subjects which had been chosen and to the level of the school. Some suggestions were provided: It is better to involve the students to use "real" English content through Google search and websites like The BBC (British Broadcasting Corporation) and the British Council resources (Robinson, 2011). Moreover, it is better to choose a simple content area covered also in the L1 and work in parallel with the L1 teacher in both languages L1/L2.

There are also many sources of materials to be used on the Internet. A particularly useful one is Wikipedia, a great source of texts, which can be legally adapted and used in class.

If language teachers and content teachers are working together, then it is vital to work as a team. If you can, observe each other's lessons and talk together. Content teachers have loads of materials; you may find equivalents in English, while language teachers will probably have new ideas on how to exploit those materials for language. It is much better to work for parallel classes together in co-presence lessons.

\section{Main Activity}

One of the first aspects to think about is the vocabulary. If there is a technical or specialist vocabulary that our students need to know, it must be pre-taught, for example, getting students to match words to definitions or pictures or making gap-fill activities. Alternatively, you could help the students discover the meanings through the text-helping them to guess meaning from context.

Therefore, the main activity should concentrate on general comprehension of the text using for instance a mind map or other follow-up activities, but never let the contents drop off. Other activities can include group discussions, individual presentations, making posters, and writing about the topic as homework or as a class activity.

\section{Operational Activities}

(1) Choose a topic;

(2) Provide a framework: a Mind Map, a Time Line, a Geographical Map; 
(3) Provide the context (where, when, why, who...) in L1;

(4) Choose an L2 text (written, oral, audio video....);

(5) Provide a glossary and a basic vocabulary (expressing dates, using past times, adverbs of location, cardinal points, etc.).

\section{Exploit the Text}

(1) Reading/listening and comprehension activities;

(2) Test the comprehension (cloze tests, oral tests, matching tests questionnaires, etc.);

(3) Work together with students in tasks helping them to acquire both language and content creating a map, a chart, a diagram, etc.;

(4) Simple and concise language has to be used at this level;

(5) Help to build the vocabulary;

(6) Help to express the contents correctly in L2-focus on questions and answers, reports through short summaries;

(7) At the same time, guide the students in order to respect and acquire the correct progression of the contents - main topic, cause and effect, timeline, geographical settings, main actors, etc., through diagrams and mind maps;

(8) Assign a task (oral or written, a text, a ppt, a video) and evaluate both content and language skills - evaluation is on two levels: contents and language. A comparative level of competence acquires in L1 and in $\mathrm{L} 2$.

\section{Class $3^{\circ}$ Media Science}

An example of a Clil unit on Electricity

\section{Text and Images}

\section{Practical examples}

\section{Glossary}

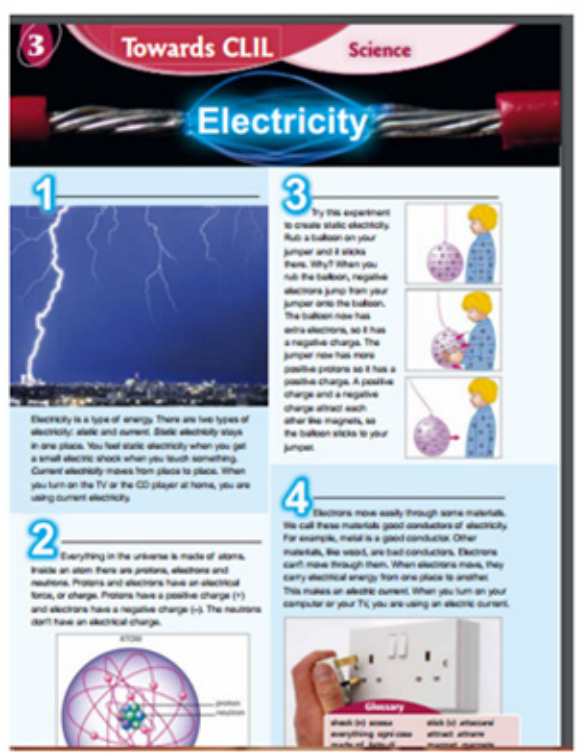

Figure 1. How to structure a CLIL lesson on science using an English course textbook.

Guided by examples provided in the basic course (Bowen \& Delaney, 2015), as the one in the figure above (see Figure 1), in a peer to peer activity in I C Laura Lanza school, the teams made up of subject teachers and foreign language teachers (English in this case) gave lessons in pairs introducing themes and work procedures to 
their students. The aim was also to provide and exploit all the ICT tools and software, which were introduced during the course, such as Edmodo, Mind map, Hotpotatoes, Kahoot, Powerpoint, and movie maker in order to produce learning objects together with the students and for the students to get the most appealing, successful, and exploitable didactic tools. Moreover, as the language of the new media is English, the use of these tools made learning easier and more motivating. All the teachers developed a set of common procedures and didactic plans: introduction of the topic, brainstorming, working on vocabulary, producing learning objects, working on texts, exploiting texts, building up oral interactions.

Here is an example of didactic plan:

SCHOOL: ICS Renato Guttuso, Villagrazia di Carini

CLASSES: 3B/3C

TOTAL MONTHS: 36

LEVEL: Medium

OPERATING MODE: Open and traditional classes

TEAM: 2 Italian, History, and Geography teachers

1 Science teacher

2 English language teachers

1 ICT teacher as a support for media tools

TITLE: "The Nazi racial state: A legalized persecution founded on scientific issues"

AIMS:

(1) Acquiring specific historical-geographic-scientific vocabulary in L2;

(2) Expressing dates and placing events in the past in L2 by setting events in a timeline;

(3) Making brief reports both in written and oral form in L2;

(4) Understanding short written and oral texts in L2;

(5) Reporting a historical event through various forms (written, oral, audio-visual) in L2.

LEVEL RANGES:

(1) High range: Pupils showing good skills and basic knowledge with an orderly working method that shows interest and participation in the activities;

(2) Mid-range: Pupils with sufficient basic training with a working method of consolidation and almost constant commitment;

(3) Low range: Pupils with partial possession of basic requirements.

EXPECTED RESULTS:

(1) Interaction both oral and written with proper vocabulary on the Topic in L2 (High Range);

(2) Answering questions both oral and written about the topic in L2 (Media Range);

(3) Acquiring and recognizing the vocabulary in L2 reusing it in structured exercises (Low Range).

METHODOLOGY:

Structured and non-verified tests (cloze tests true/false, multiple choice, matching exercises, questionnaires, spider diagrams, mind maps), Laboratory Didactics, Group Work, Frontal Lesson, Inductive and Deductive Methods.

TOOLS AND MEDIA: Multimedia board, disciplinary textbooks, Internet (Google, YouTube, Wikipedia) 
USED SOFTWARE: Word, Excel, Mind map, Edmodo Platform, Adobe Reader

TESTING: Online quiz on Edmodo-Oral Interview

\section{The School Network at Work}

A lot of work was to be carried on as one of the obstacles the teachers had to face was the lack of materials, in particular materials adequate to the level of the students and also because the assumption was that it has not to be provided a subject text in English as a foreign language but a text with a range of adequate exercise of comprehension and exploitation of the vocabulary, such as shown in Figure 3, and of the functions and structure as the aim was that of providing a frame work for Content and integrated language lessons, so the main resources were the net with Google search on the topic and the textbooks. Most of the English course text books were taken as an example on how to build a CLIL lesson, but the teachers produced many documents, Powerpoints, interactive exercises, and videos and a huge work had to be done by the teachers at home. The students, in particular the students of the third classes of low secondary school, were also guided by the teachers to produce their own materials as Powerpoint presentations and maps, as it can be shown in Figure 2, after a double check of content and language teachers were included in the folder of the learning objects that this work group did.

\section{Mappa concettuale:}

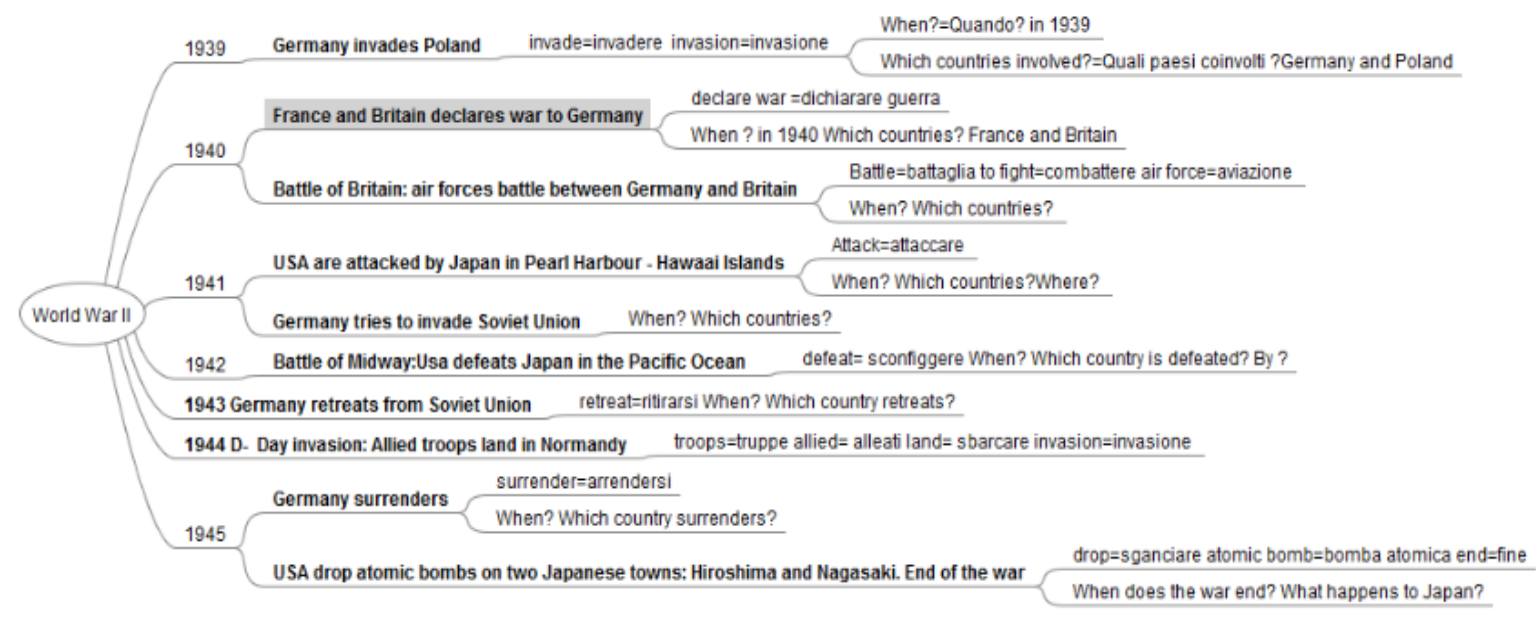

Figure 2. An example of map on World War II events built up using free Mind tool.

The materials are still uploaded on the Edmodo platform of the project, a platform that was used to monitorate and evaluate the project and to collaborate and give hints and information among the teachers involved. Some examples of the learning objects can be seen at the following link:

https://www.youtube.com/channel/UCdTdCf5YQTofONzhD5eafZA

The teachers also opened an Edmodo class in their schools with their students in order also to provide and share materials in particular for testing. It was easier to use Edmodo quizzes as structured tests to evaluate the knowledge and the competences of the students. Competences were evaluated through testing: cloze tests, oral tests, building up of maps and learning objects, virtual presentations, and videos. The evaluation took into account both content and language, specific vocabulary and terms, and the use of correct tenses. 


\begin{tabular}{|c|c|}
\hline Against & Contro \\
\hline Air force & Aeronautica Militare \\
\hline Air craft & Aeronautica \\
\hline Aircratft carriers & Portaerei \\
\hline Alliance & Alleanza \\
\hline Allied & Alleati \\
\hline Attack & Attacco \\
\hline Battle & Battaglia \\
\hline Bombers & Bombardieri \\
\hline Campaign & Campagna \\
\hline Conflict & Conflitto \\
\hline Conquer & Conquistare \\
\hline Conquest & Conquista \\
\hline Damage & Danneggiare \\
\hline Decide & Decidere \\
\hline Declare & Dichiarare \\
\hline Declaration & Dichiarazione \\
\hline Destroy & Distruggere \\
\hline Drop & Lanciare \\
\hline East & Est \\
\hline Enemy & Nemico \\
\hline Escape & Fuga \\
\hline Fight & Combattimento \\
\hline Invade & Invadere \\
\hline Invasion & Invasione \\
\hline Miles & Miglia \\
\hline Naval force & Forza navale \\
\hline North & Nord \\
\hline Planes & Aerei \\
\hline Policy & Politica \\
\hline Request & Richiesta \\
\hline Reaction & Reazione \\
\hline Ships & Navi \\
\hline Sink & Affondare \\
\hline Surrender & Resa \\
\hline South & Sud \\
\hline Times & Volte \\
\hline
\end{tabular}

Figure 3. An example of vocabulary support linked to the text.

\section{Comparing the Results}

The work was made also in parallel classes, CLIL and No CLIL classes, so that the results of the shift in competences could be more easily acquired. The results of the path were collected through a survey monkey test in which teachers were asked to compare the level of both content and vocabulary in the classes involved in the project and in the classes not involved in the project. Making a comparison with traditional classes, the results proved that the students had acquired the same content as in mother tongue lessons although expressed in a basic way and had gained a wider vocabulary and a larger use of language to express past events. Compared to normal classes, they were more used to report past events referring also to situations excluding their personal experience. Moreover, they had acquired a better level of comprehension of several typologies of texts and this skill was expendable during final term exams. A survey conducted among the students had proved an increase of motivation and interest in continuing the use of CLIL as a new way to approach disciplines, such as History or Geography, which they previously considered rather boring. A survey among teachers had proved that this experience had improved cooperation and exchange of good practices and good 
teaching methodologies in order to make the teachers' team work more effective and more successful within their classes and the school. In fact, this project was repeated the following year among the same schools but with a different approach. Testing and evaluation were performed through the use of the platform Edmodo and this was a good chance to implement and foster virtual classrooms as a way to promote both collaboration, peer to peer learning, and widen school timetable. But as an evaluation tool, tests provided by the platform proved to be easy for the teachers to build up, easy for the students to take, and enough flexible for all the levels of the students and provided an immediate feedback within. An example is provided below and a reading text whose source was an English language class book (Bowen \& Delaney, 2015) was adapted to perform an evaluation test on CLIL topics referring to the topics chosen for the project.

Totale punti: 1

Read the text and answer: When did The War between Britain and Germany begin?

\section{Beading, comprehension}

\section{World War evacuees*}

evocuees - sfollati

evocuotion - evacuasione

1.5 million women and children moved from the city to the countryside in the weeks before Britain declared

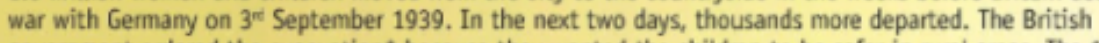
government ordered the evacuation* because they wanted the children to be safer in rural areas. The 1939 evacuation was the biggest movement of people in British history.

Taking the train Hundreds of thousands of children left their homes in cities and went by train to stay in small towns and villages in the countryside. The children didn't know where they were going or when they were coming back - some even thought they were going on holiday. The children often went with their teachers and wore the name of their destination on a sign around their necks. When they arrived in

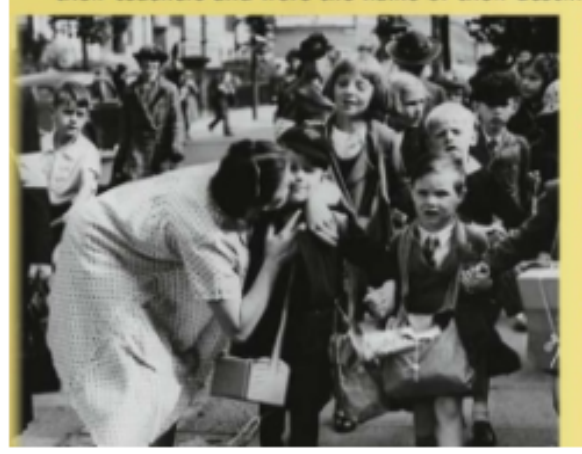
the towns or villages, they went to live with local families and they went to school there. It was a journey which dramatically changed the lives of all the children. Country life Through evacuation, many city children had their first experience of life in the countryside. They played in the woods and learnt that milk came from cows. Some evacuees had very happy times with their host families, but some were not treated well and were very homesick. In fact, the bombing didn't begin until nearly a year later and some children returned home. When the bombing began, the children were evacuated again. The war ended in 1945 and a total of 3.5 million evacuees returned to their homes.

Domanda: 2

Totale punti: 1

Why did the British government send children to the countryside?

Because they had no space in their towns

Because they wanted them to stay in a safer place

Because they wanted they lived in touch with Nature

Figure 4. An example of test built up through Edmodo platform. 


\section{Conclusion}

CLIL is not an impossible challenge in the Italian school system provided that the approach changes. ICT has proven to be really effective in managing contents and language issues both for students and teachers, but unfortunately, the general low level of English language competence of Italian subject teachers has not allowed so far a proper development of CLIL in Italian schools. Only by the spreading and sharing of projects of this kind and an adequate cooperation among the subject teachers and the English language teachers and the extensive use of ICT tools in order to create in cooperation new and more appealing learning objects can plant the roots of a successful CLIL approach in schools in Italy.

\section{References}

Bowen, P., \& Delaney, D. (2015). High spitits (Vol. 3). Oxford: Oxford University Press. Retrieved from www.oup.com/elt Robinson, B. (2011). World War Two: Summary outline of key BBC London events. Retrieved from http://www.bbc.co.uk/history/worldwars/wwtwo

\section{Appendix}

Dipartimento Politiche Europee http://www.educazionedigitale.it/percorsi/europa-noi EDMODO www.edmodo.com

eTwinning www.etwinning.net

Start Up CLIL Network, Towards Clil project, school year 20152016 referent teacher Emanuela Leto

Headmaster prof. Giampiero Finocchiaro

Wikipedia simple pages https://en.wikipedia.org/wiki 